\title{
Novela como nube o Narciso en los espejos
}

\author{
Novela como nube or Narcissus at the mirror \\ Celene García Ávila \\ Universidad Autónoma del Estado de México, Toluca, México. \\ Correo electrónico: celviravila@gmail.com
}

En Novela como nube (1928), de Gilberto Owen, la multiplicación del yo manifiesta la toma de conciencia acerca del carácter incompleto y permanentemente escindido del sujeto, que es siempre otro, los otros. Se analiza en este trabajo el aspecto lúdico que se desprende del planteamiento de la trama, así como la relectura del mito de Ixión que se elabora en el texto, a la luz de las propuestas vanguardistas de la época, como el Surrealismo o el Dadaísmo.

Palabras clave: novela lírica, Gilberto Owen, narrativa lúdica, vanguardia.

Gilberto Owen wrote in 1928 Novela como nube, an experimental nouvelle. The aim of this article is to analyze the incomplete and divided self which is portrayed as a myriad of fragments and different voices in this work. Also discussed here is the interpretation of Ixion's myth developed throughout the story as though the narrator were playing games, following one of the main avant-garde proposals, such as Surrealism. The article expects to show Owen's interest in movements such as Surrealism or Dadaism.

Key words: lyrical novel, Gilberto Owen, narrative games, avant-garde.

“[...] es en mí donde tú estabas, / porque tú estás en todas partes” (Sindbad el varado, "Día veintidós, tu nombre, Poesía”, 83).

\section{NOVELA COMO NUBE: UN EJERCICIO LÚDICO}

En Novela como nube (1928) el protagonista Ernesto y sus múltiples sombras no tienen una sola faceta; el protagonista convive con sus recuerdos y con sus deseos parece desdibujar el presente, tal como un héroe moderno que no se contenta con remedar a un antihéroe de la antigüedad griega (con un perdedor y un castigado), sino que ni siquiera la trama de sus actos alcanza la altura de un semidiós. No en vano se cita en Novela... a Joyce y sus “diálogos en espiral”. Se trata de internarse en la vida interior de un antihéroe anodino y moderno, aspirante a poeta, trasnochado, cuya vida transcurre en la indefinición entre los amores con Eva I y Eva II, con Ofelia y Elena, con ésta y Rosa Amalia. Cabe señalar el sentido lúdico del texto.

Si se recuerdan las ideas de Rodó al analizar el lugar de América Latina frente al de América del Norte y Europa, podrá reconocerse la vigencia de la crítica del uruguayo, 
quien, en 1900, se manifestaba en contra de la visión racionalista y utilitaria del mundo para contrastarla con una actitud estética y contemplativa. El ensayista lamenta que “soñar, pensar, admirar”, tres acciones fundamentales para los seres humanos, se interpreten como negativas dentro de las sociedades actuales que privilegian la razón y la utilidad en deterioro de la vida interior. Afirma Rodó que los antiguos clasificaban esas tres acciones — que aseguran la integridad de la condición humana- dentro de la “noble inteligencia del 'ocio', que ellos tenían por el más elevado empleo de una existencia verdaderamente racional, identificándolo con la libertad del pensamiento emancipado de todo innoble yugo. El ocio noble era la inversión del tiempo que oponían, como expresión de la vida superior, a la actividad económica” (1982: 27).

El carácter lúdico de Novela..., así como de otras ficciones de vanguardia, está en consonancia con la defensa del ocio que expone Rodó; el hecho de renunciar a la utilidad de la narración atenta en contra del presupuesto acerca de que este género debe servir para algo (la educación moral del público, por ejemplo). Gilberto Owen espera que el lector se convierta en un compañero de juegos. Quizá por eso la identidad del narrador y también del personaje se deslizan con insistencia.

La puesta en práctica de la narración como una actividad lúdica, en la cual se rompe la linealidad de la trama, implica la afiliación con la estética de las vanguardias, las cuales compartían el deseo de subvertir los cánones y cuestionar o rechazar la herencia histórica y cultural. El juego es siempre el instante presente en el cual el "yo" que crea un narrador para contar el cuento espera que el otro, el lector, lo complemente: en el texto se juega para reacomodar las piezas constantemente.

En este sentido, Novela como nube hace eco de las afirmaciones que en 1925 expresa José Ortega y Gasset respecto del arte nuevo y, en particular, de la novela de vanguardia que no toma en serio la realidad: "El rencor va al arte como seriedad; el amor, al arte victorioso como farsa, que triunfa de todo, incluso de sí mismo, a la manera que en un sistema de espejos, reflejándose indefinidamente los unos en los otros, ninguna forma es la última, todas quedan burladas y hechas pura imagen” (1983: 40). Posteriormente, subraya que, en aras de escapar a la seriedad de la vida, el arte nuevo se propone a sí mismo como intrascendente y, más bien, se aproxima al deporte y a los juegos; la novela nueva de los años veinte se acercaba, según el estudioso español, al cinematógrafo, coincidiendo con este en que resaltaba el "arte corporal” (1983: 40).

Gilberto Owen merece ser escuchado como un hábil tirador de dados que mantiene a su comparsa-lector en la frontera entre la realidad externa que se palpa y el carácter íntimo de la vida interior. En este aspecto, Gilberto Owen hace eco de la concepción del arte que defendía Dadá:

DADA n'est pas folie, ni sagesse, ni ironie, regarde-moi, agréable bourgeois.

L'art était un jeu noisette, les enfants assemblaient les mots qui ont une sonnerie à la fin, puis ils pleuraient et criaient la strophe, et lui mettaient les bottines des poupées et la strophe devint reine pour mourir un peu et la reine devint baleine, les enfants couraient à perdre haleine (1963: 16). ${ }^{1}$

\footnotetext{
"Dada no es locura ni sabiduría ni ironía, mírame, gentil burgués.

El arte era un juego avellana, los niños juntaban las palabras que tenían un timbre al final, después lloraban y gritaban la estrofa, y le ponían los botines de las muñecas y la estrofa se convertía en reina para morir un poco y la reina se convertía en ballena, los niños corrían hasta perder el aliento” (La traducción es mía). Nótese que Tzara juega con la proximidad fonética de algunas palabras, así como con el sentido fortuito entre unas frases y otras.
} 
Owen se muestra como un prestidigitador que ha frecuentado a James Joyce y a T. S. Eliot, quienes en 1922, con Ulysses y The Waste Land, respectivamente, exponen la riqueza y complejidad de los seres enfrentados a su cotidianeidad, así como la importancia del recuerdo, del sueño y del deseo, nunca asibles en órdenes lineales de discurso, espacio o tiempo. De esta manera, a pesar del proceso de banalización al que se somete la historia de Ixión en la trama de Novela como nube, el mito reelaborado por el poeta moderno, Ernesto conserva su capacidad de inquietar al personaje desde el interior de su vida psíquica: revela los miedos y las frustraciones del personaje principal (véase Torres Souza y Barbosa Rocha 2009). ${ }^{2}$ Como técnicas, la fragmentación, la polifonía, el soliloquio, el monólogo interior, la superposición de planos narrativos, espacios y tiempos, la combinación de registros de lengua coloquiales con registros figurados más elaborados. Las vanguardias rompen con la idea de que la obra de arte debe ser trascendente y ornamental.

Dice Milán Kundera que lirizar la novela significa "renunciar a su esencial ironía, apartarse del mundo exterior, transformar la novela en confesión personal, sobrecargada de elementos”, de modo que el género novelístico se caracteriza como "poesía antilírica” (2004: 158-159). Ciertamente, parecería que en las novelas experimentales de los años veinte los autores tratan de mantener al margen de sus historias cualquier contacto objetivo con la realidad, pero esto no significa que en todos los casos se haya prescindido de la "esencial ironía” que muestra la crisis entre el sujeto y el mundo. Porque el rechazo al arte realista es uno de los motores que impulsan la experimentación narrativa de las vanguardias. Susan Sontag trata de entender esa negativa a compenetrarse con las realidades exteriores como una respuesta posible a la frustración de no poder crear ya nada nuevo: "Para compensar esta ignominiosa sujeción a la historia, el artista se exalta con el ensueño de un arte totalmente ahistórico y, por lo tanto, no alienado (1985: 24).

Una de las virtudes del relato de Owen es, precisamente, esa duda respecto de la identidad del narrador-protagonista y de la certidumbre de sus acciones, ubicadas a medio camino entre la ensoñación y el recuerdo, razón por la cual la recurrencia a un mito griego se convierte en una estrategia narrativa más para tratar de confundir al lector. No debería asignarse a lo lúdico un sentido peyorativo. Al contrario, habría que reconocer que en el arte los actos de "jugar y juguetear”, incluso en su acepción de "retozar amorosamente, yacer carnalmente", no tienen un sentido despreciativo: hay que "yacer carnalmente” con el texto. Y en Novela como nube Narciso dialoga en los espejos, de modo que el lector también deberá internarse en Novela... torciendo su mirada en las imágenes múltiples que le va ofreciendo el texto; para ello, tiene que romper esa resistencia a leer jugando.

\section{UNA NOVELA DE VANGUARDIA}

Lectura obligada para los escritores hispanoamericanos que se mantenían atentos a las manifestaciones artísticas francesas fue el Primer manifiesto del surrealismo (1924), de André Breton. No todos estuvieron de acuerdo con la propuesta de que

\footnotetext{
En el artículo de Torres Souza y Barbosa Rocha (2009) se explica la importancia del mito para estudiosos como Freud y Lacan, quienes pensaban, con sus diferencias teóricas y metodológicas, que los mitos podían ofrecer ayuda para comprender algunos procesos inconscientes; además, Lacan subrayó el carácter liberador del mito, ya que repite temas básicos ligados a la existencia del sujeto.
} 
habría que entregarse al "automatismo psíquico puro”, en el cual se trataba de captar, lo más pasivamente posible, el "dictado del pensamiento, con exclusión de todo control ejercido por la razón y al margen de cualquier preocupación estética o moral” (Breton 2001: 44); no todos estaban dispuestos a hacer suya la máxima de trabajar bajo el influjo de la escritura automática "con loable menosprecio por las consecuencias literarias".

Sin embargo, algunos como Gilberto Owen sí muestran interés por las libertades que las vanguardias proponen para la creación. Por ejemplo, la riqueza de la imagen y su capacidad para violentar el "reinado de la lógica” (Breton 2001: 26). Breton hace suya la definición de Reverdy; Owen, por su parte, lleva a la práctica el arte de la disociación y cree también que la imagen será más intensa y "tendrá más fuerza emotiva y realidad poética cuanto más distantes y precisas sean las relaciones entre las dos realidades que se ponen en contacto" (citado en Breton 2001: 38). La belleza depende — según Breton— del "fulgor de la imagen a cuyo brillo somos infinitamente sensibles”, es decir, habrá más belleza cuanto más disociados estén entre sí los términos que participan en la creación de la imagen. En otras palabras, a mayor arbitrariedad, mayor belleza y mayor grado de certeza entre la palabra y el espíritu. En la imagen surrealista los objetos (el referente) son otros.

Novela como nube podría relacionarse con la novela de artistas — como À rebours, de Huysmans, o De sobremesa, de José Asunción Silva—; sólo que, a diferencia del tono más bien serio y reflexivo de estas, el protagonista carece de cualidades encomiables, lo cual contradice la finalidad de este tipo de narraciones. Por otra parte, la composición del discurso es muy cercana a la poesía y abundante en sentidos figurados, gracias a la importancia que Owen concede a la imagen: "El mar, viejo barítono, ocultaba en el bolsillo de su verdiamarillo chaleco de fantasía la moneda del sol, jornal de todo un día de trémulos guturales” (1979: 150). ${ }^{3}$ En Novela... (escrita en 1926 y publicada por Ediciones Ulises en 1928) se cuenta el mito de Ixión en el siglo XX. Un tono entre cómico y amargo se emplea para reflexionar sobre el lugar del artista en la sociedad cada vez más industrializada y mecanizada del siglo XX.

Se establece, entonces, el primer diálogo entre dos obras, dos épocas y dos códigos. La intención paródica consiste en que la presencia de las divinidades griegas se cubre de un "sutil, insoslayable escarnio [que] envuelve el todo y lo vuelve lábil, huidizo” (Calasso 2002: 76). Calasso explica en La literatura y los dioses de qué manera las divinidades del Olimpo griego degradan su presencia y vigencia cuando autores románticos, como Hölderlin o Schlegel, las incluyen en sus obras. Calasso comenta el punto de vista de Nietzsche, quien consideraba que el hombre moderno trataba de dar respuesta a la sensación de desorientación y de falta de creencia en “fábulas” o leyendas mitológicas; en consecuencia, pensaba que era posible dar lugar a nuevos dioses; sin embargo, también veía que en esa búsqueda el hombre de los nuevos tiempos, “'sin quererlo y por rebosante plenitud y poder, juega con todo lo que hasta ahora había sido considerado como sagrado, bueno, intocable, divino””.

Habría que señalar, por otra parte, que el hecho de que Owen haya elegido el mito de Ixión también tiene que ver con la ambigüedad propia del mito, pues si bien éste es una ficción narrativa, contiene a su vez una verdad velada, que quizá no podría decirse de otra manera (Torres Souza y Barbosa Rocha 2009). Ahora bien,

En adelante citaré por la edición del Fondo de Cultura Económica, Colección Letras Mexicanas, de 1979. 
Owen compone ciertas variaciones sobre el argumento del mito de Ixión que se analizarán más adelante, pues para ello, es necesario resumir el mito griego. Ixión iba a desposarse con Día y, por no pagar a su suegro lo que le había prometido a cambio de la futura esposa, lo asesinó arrojándolo a un horno. Ningún dios quería purificarlo de su crimen, pero Zeus se apiadó de él y lo perdonó. Para celebrarlo, lo invitó a comer al Olimpo, donde Ixión trató de seducir a Hera. Cuando Zeus constató las intenciones de su invitado, formó con nubes a una Hera falsa, Néfele, a quien sedujo Ixión. Zeus lo golpeó y lo condenó a girar incesantemente atado a una rueda que dejó caer desde el Olimpo hasta el Tártaro; el hijo de Néfele e Ixión fue Quirón, un Centauro (Falcón Martínez 1989: 363-364).

\section{LA REESCRITURA DEL MITO DE IXIÓN}

El texto de Owen tiene dos partes: "Ixión en la tierra” e "Ixión en el Olimpo", cada una de trece fragmentos. Néfele está trazada sobre la imagen de Hera falsa. Ixión, además de quebrantar las normas, carece de decoro; el personaje se muestra ingrato y soberbio, por eso su condena es infinita. En el texto de Owen las acciones parecen estar sujetas al azar del recuerdo, la memoria o la imaginación; a la manera de Proust, algunos detalles desencadenan digresiones. Además, el título tentativo de Novela... era Muchachas, en la misma veta de la novela proustiana, A la sombra de las muchachas en flor, en la que un joven se debate entre el amor de dos mujeres; este tema es común a las obras de Gilberto Owen (Novela...), Xavier Villaurrutia (Dama de corazones) y Torres Bodet (Margarita de niebla) (Véase Sheridan 1985: 304-310).

Los atrevimientos de Ernesto - el personaje principal— fracasan tanto como los de Ixión, pero son menos audaces porque este personaje es francamente anodino, lo cual establece un diálogo paródico entre el mito griego y la novela experimental de Owen, pues el Ixión del mito manifiesta rasgos reprobables como la avaricia y el abuso de confianza, razones por las cuales es castigado, en tanto que el personaje de Owen no pasa de la medianía del "fantoche". Cuando Ernesto se mira en el espejo de sus zapatos, la imagen no enaltece, minimiza: "Ernesto marcha inclinado sobre los espejos del calzado, sucesivos. Se ve pequeñito” (146). Ernesto conserva un rastro casi cómico de Narciso; el ambiente bucólico de la fábula original cede su lugar a la cárcel pulida de los zapatos, en donde apenas, apenitas, el menguado protagonista alcanza a verse no en una sola y viva imagen, sino en pequeños reflejos múltiples.

En el segmento 20, titulado "la víctima”, aclara el narrador: "Lo único que deseo es dibujar al muñeco Ernesto y a dos muchachas lo mismo de falsas que él [...]. Lo patético sería — ved que sí lo comprendo - el choque de la curiosidad de las dos muchachas —azuzadas por los ojos borrascosos de Ernesto- con el miedo atmosférico de Pachuca. Pero tampoco es eso lo que quiero. Estoy a punto de reconocer que todo lo escrito hasta aquí puede ser pasado por alto” (174). En el segmento 18, titulado "unas palabras del autor", se insiste en los procedimientos elegidos para crear al protagonista Ernesto:

Ya he notado, caballeros, que mi personaje sólo tiene ojos y memoria; aun recordando sólo sabe ver. Comprendo que debiera inventarle una psicología y prestarle mi voz. ¡Ah!, y no prestármela mitológica. ¿Por qué no, mejor, intercalar aquí cuentos obscenos, sabiéndolos yo muy divertidos? Es que sólo quiero dibujar un fantoche (171). 
A diferencia de Breton, quien inocentemente se deja guiar por sus paseos deambulatorios para ver qué le depara el azar en Nadja, en Novela como nube se subraya la distancia entre la voz del narrador y de su personaje (al cual le presta la voz), con lo cual el autor subraya el carácter ficticio de su obra, así como la intención que tiene de crear "un fantoche".

Los fragmentos 18, 19 y 20 son un paréntesis que se emplea para explicar y justificar la manera de proceder del escritor de Novela... Por primera vez, el narrador habla en primera persona para defender su creación como si se tratara de un prólogo; si Ernesto fue trapecista, el autor es alambrista:

Me anticipo al más justo reproche, para decir que he querido así mi historia, vestida de arlequín, hecha toda de pedacitos de prosa de color y clase diferentes. Sólo el hilo de la atención de los numerables lectores puede unirlos entre sí, hilo que no quisiera yo tan frágil, amenazándome con la caída si me sueltan ojos ajenos, a la mitad de mi pirueta. Soy muy mediano alambrista (170-171).

El autor-personaje tiene plena conciencia de sus objetivos y limitaciones. Habla de "numerables" lectores porque sabe las dificultades de su creación. Dice que es "mediano alambrista" porque no ha dispuesto las piezas de su prosa en un orden lineal y cronológico como otras novelas. Un comentario indica el procedimiento que el autor ha seguido en la elaboración de su personaje: "el determinismo quiere, en mis novelas, la evolución de la nada al hombre, pasando por el fantoche. La escala al revés me repugna” (171); no hay intención pedagógica alguna en un autor que escribe para unos cuantos.

Ahora bien, todo este desprendimiento del autor y del narrador respecto del personaje, más bien convertido en "muñeco", tiene mucho en común con lo que Breton recomienda para la elaboración de "falsas novelas": los personajes han de ser una contradicción, es decir, se comportarán como impersonales, tendrán “un número limitado de características físicas y morales", suficientes para que esos seres no se aparten de "una determinada línea de conducta”, acerca de la cual —insiste Bretonel autor no necesitará ocuparse. A diferencia de Breton, Owen tiene bien clara la línea divisoria entre las experiencias vividas por el autor y el esfuerzo creativo que como novelista experimental lleva a cabo.

Hasta aquí, podría anticiparse que si bien Owen no se concibe como un practicante de la escritura automática, puesto que no está dispuesto a dejar de lado la intención estética del texto para capturar la vida del inconsciente, sí tiene la audacia suficiente como para hacerse de algunas técnicas de escritura expuestas por Breton (y por otros autores de vanguardia, como Tzara o Marinetti), con el fin de mostrar la vida interior de su "fantoche".

El narrador constantemente explica las actitudes de sus personajes con comentarios humorísticos y hasta sarcásticos, de manera que esta novela como nube pierde el dramatismo del mito original. Por ejemplo, hay ciertos juegos de palabras a tono con la medianía del personaje: "Un camino quedaba que daba a la parte media de la colmena, pero esto no quiere decir que la burocracia sea sólo para los zánganos” (146). Sheridan llama la atención sobre este aspecto: Novela... es la única —entre las prosas de los Contemporáneos- en la que "el humor opera como disparador del punto de vista” (1985: 308). 
Ernesto adquiere personalidad ante los ojos del lector por medio de miradas parciales y externas: el narrador lo va presentando por medio de otras voces para describirlo en fragmentos que le dan forma por medio de sinécdoques y metonimias. Desde el primer fragmento de Novela..., el "Sumario", se descubren los mecanismos que el autor aplica en su prosa: un narrador en tercera persona da a conocer a su personaje indirectamente - como si se tratara de breves acercamientos cinematográficos, acompañados de voces que dejan ver claramente partes del protagonista o de su entorno, pero no revelan la imagen completa. En el "Sumario" se narra escondiendo a los personajes y sus acciones detrás de situaciones ajenas a la anécdota.

El texto, en lugar de volcarse al exterior, se encierra en la intimidad del personaje. Owen recurre al prototipo del poeta extravagante y bohemio, cuando el narrador alude a las rosas y los claveles, respecto de los cuales comenta que "avergüenza ya pronunciar”. Es decir, el narrador marca su distancia respecto de su héroe; en la primera parte ("Ixión en la tierra”), se narra todo el tiempo en tercera persona. Los Narcisos o reflejos se convierten en el verdadero centro de interés del narrador. Ernesto-Ixión es el acróbata arrojado desde el Olimpo hasta el Tártaro (la caída sin fin), condenado a la rueda de la rutina matrimonial.

\section{El JUEGO LITERARIO CON LO AUTOBIOGRÁFICO}

En varios de los fragmentos que forman la novela, hay referencias a la vida de Gilberto Owen (dichas alusiones se encuentran en las cartas, las notas autobiográficas, los poemas y otras prosas). Esto ha sido motivo suficiente para interpretar que el yo de Novela... es un yo autobiográfico (Domínguez Michael 1994); parece fácil relacionar al poeta Ernesto - que no cuenta con la aprobación de su creador- con el poeta Gilberto. Pero es una conclusión fácil en tanto que no se aclare que lo autobiográfico pasa a formar parte de la ficción: algunas de las noticias que se tienen acerca de la biografía de Owen se encuentran ficcionalizadas o mitologizadas dentro de la obra del escritor. Aun datos reales como la fecha de nacimiento se someten a la ambigüedad, ${ }^{4}$ de tal manera que empieza a borrarse la frontera entre lo real y la ficción.

Por eso, "la vida real del poeta Gilberto” intercalada en la novela debería señalarse entre comillas, porque Owen se esforzó en hacer de su vida literatura, alterando y recomponiendo los datos reales. Owen se entrega completamente a su juego, cuando habla de "sí mismo" en la novela sobre el muñeco fantoche, Ernesto. Por ejemplo, se

\footnotetext{
Owen aseguró a algunos de sus amigos que había nacido en 1905 (Véase Arredondo 1982: 43-48). En una carta a Xavier Villaurrutia dice haber nacido en 1904 (263). En "Bitácora de febrero", el poeta asegura: "Todos los días 4 son domingos / porque los Owen nacen ese día" ("Día cuatro, almanaque”, en Sindbad el varado, 71). En su acta de nacimiento se signa la fecha: "Queda registrado á fojas 86 [...] el nacimiento del niño Gilberto Estrada, ocurrido en esta ciudad [Rosario, Sinaloa] el día 13 del corriente mes á las dos de la mañana”. El registro se llevó a cabo el 26 de mayo de 1904 (Expediente de Gilberto Estrada, 1919, Archivo de la Universidad Autónoma del Estado de México, caja 171, 6646). Por otra parte, la fe de bautismo dice : “[...] el Sr. cura D. Felipe de F. Elizondo bautizó solemnemente [...] a Gilberto que nació en esta ciudad [Rosario, Sinaloa] el día primero de mayo del presente año [1904] hijo natural de Margarita Ayala abuelos maternos Jesús Estrada y Matilde Ayala [...]” (Transcripción que reproduce José Hilario Ortega 1988: 37). Puede confirmarse en el Archivo de la Parroquia de Nuestra Señora del Rosario, Sinaloa, México (vol. 43, años 1903-1905, libro 8, foja 48). Podría concluirse que el nombre, el padre y el nacimiento se convierten en obsesiones literarias probablemente por haber sido hijo natural y no reconocido por el padre, hechos que se proyectan en la obra de Owen como conflictos de identidad, expuestos muchas veces con ironía o sarcasmo, frecuentemente enmarcados en contextos paródicos.
} 
logra el tono irónico del principio en la siguiente expresión: "Su amigo el ingeniero de ingenios le reprochaba el ser lampiño. ¡Qué triste! No poder comparar en un poema las delicias de rasurarse con la estancia en Nápoles. La comparación de la rasurada con Nápoles es un alarde de la asociación sorpresiva que tanto gustó a los surrealistas; la comparación y la exclamación irónica (“iQué triste!”) pertenecen al registro de voz del personaje. Por referencias externas, se sabe que Owen llamaba a su amigo Jorge Cuesta "el ingeniero del ingenio” (Sheridan 1985: 274). "La vida real del poeta Gilberto" (entre comillas) se filtra en toda la historia.

Una anécdota que Owen refiere en "Encuentros con Jorge Cuesta" se retoma en Novela... En el texto de carácter autobiográfico se recuerda que un profesor de la Preparatoria Nacional dijo un disparate y fue increpado por Gilberto Owen:

“¿Cómo iban a caminar esos ejércitos, día y noche, bajo los rayos del sol?” El silencio de segundos que siguió a mi impertinencia se rompió de pronto, cuando mi compañero de la izquierda se echó a reír. Ruidosamente, con una áspera risa, echando la cabeza hacia atrás (240).

Así se inició la amistad entre Owen y Cuesta. En Novela... simplemente se cita: "Aquel profesor de historia que refería: 'noche y día, bajo los rayos del sol, los ejércitos...". Puntos suspensivos. En este diálogo entre la ficción y la "vida real" se quiebran las fronteras. Al cambiar de contexto las palabras citadas, se modifica el sentido, por eso prefiere la reticencia a la cita completa. ¿Qué interpretará el lector? ¿Que Ernesto empieza a recordar cosas, sin el menor interés en que los demás comprendan?

Ernesto sufre la abulia gideana, que Villaurrutia prefería llamar ataraxia. Aquí aparece Sindbad, el héroe con quien se identifica "el poeta Gilberto", solo que en la inversión del espejo, es decir, el botellón donde el protagonista se entrega a la divagación de la imagen distorsionada de la mujer que le quita el sueño (Ofelia) y de él mismo, en "una marina crepuscular [...] como un conocido anuncio de dentríficos" (149). En este pasaje irónico (también una parodia de los retratos de novios) se explica el mito oweniano, el símbolo íntimo del marinero: "ya no recuerda si fue la anécdota que le supone nacido en el mar y llamado también Sindbad, o si repitió simplemente la que mayores éxitos le ha dado, aquella que le fruncía el entrecejo para que se leyeran en él cosas de gambusinos y filibusteros". Vida y literatura se entretejen en el enunciado; se borra la línea divisoria. El “yo autobiográfico de Owen es un yo literario que está en continuo desdoblamiento. Vale recordar que Owen no conoció a su padre y que en la obra de este escritor hay una obsesión por un retrato masculino de perfil, que se asocia con el gambusino irlandés (imagen relacionada con el padre de Owen), a quien supuestamente asesinaron en Rosario, Sinaloa. Sobre este tema se lee en Sindbad el varado, "Día tres, al espejo”, lo siguiente:

[...] si gritan el mío [mi nombre] responden muchos rostros que yo no conocía o que borró una esponja calada de minutos,

como el de este párvulo que esta noche se siente solo e íntimo

y que suele llorar ante el retrato

de un gambusino rubio que se quemó en rosales de sangre al medio día (70-71).

Si se siguen tirando los dados (puesto que el lector hace su trabajo), aparecerá en Novela... el número trece. El camarote de Ernesto en el barco tiene el número trece; el 
fragmento donde se narra la muerte del personaje corresponde al mismo número. No se trata de una coincidencia. En la obra de Gilberto Owen los números tienen un valor simbólico; el trece es un número fatal: en la mitología oweniana, el trece de febrero alude a la muerte del padre, que quizá Gilberto sólo conoció en un retrato de perfil (eso podría explicar el hecho de que Owen eligiera el 4 de febrero, en lugar de mayo, como la fecha de su nacimiento; la identificación con el padre se logra literariamente en la proximidad de las fechas: febrero, nacimiento y muerte).

En una carta a Margarita y a José Rojas Garcidueñas, después de reseñar la vida de otros Owen registrados en las enciclopedias, dice el poeta: “Otro [Owen] se fue a Sinaloa y se dedicó a abrir minas y a dar a luz a los 3000 personajes que se resumen en Gilberto Owen. Lo mataron un día trece de febrero, en las calles del Rosario. En fin, hemos hecho muchas cosas en público, menos llorar" (294). En Sindbad el varado, "Día cuatro, almanaque", el poeta - no el padre- muere un martes trece, con toda la carga de superstición que implica la frase: "Y, además, que ha de ser martes el 13 / en que sabrán mi vida por mi muerte” (72). Ernesto, uno de los tantos personajes de Gilberto Owen (que no el yo autobiográfico del escritor "de carne y hueso"), también ha de morir un día trece: inicio y fin; porque esa muerte que no es posible verificar físicamente en el personaje es el pase de la tierra al Olimpo; es más bien un despertar que pareciera ocurrir dentro de un sueño.

En los trece episodios de la segunda vida de Ernesto, será imposible buscar la diferencia entre lo real y lo imaginario. El narrador tiene la necesidad de expresarse en primera persona de vez en cuando, y permite que Ernesto se comunique, también, con una voz propia. Se conserva la mirada introspectiva del personaje, que está marcada por el impedimento de Ernesto para abrir los ojos; entonces, escucha, huele y palpa. Su enfermera es Elena, quien fuera, "en la otra vida”, la novia de Ernesto, aunque, al final, se entregara al tío de aquél.

El autor de Novela... y el protagonista fantoche persiguen una exploración poética. En la nueva vida también se recuerda, se duerme, se sueña y se lee el periódico (que podría aludir al ocio). En la segunda parte Ernesto sueña con su doble, "el ángel Ernesto”, quien tiene veinticinco años más y, al mismo tiempo, es una réplica del tío Enrique. Ernesto sueña el retrato y se lamenta por no haber aprendido el lenguaje que hablaba aquella imagen; no queda claro a quién representa el retrato. Hay una situación similar que se describe en "Naipe”, una de las prosas de Línea: "El hombre que es sólo una fotografía de mi padre — nada más en la noche, el rostro y la barba más blancos que la blancura-, ese hombre afirma que es yo" (57).

La obra de Owen está en constante diálogo consigo misma, como los espejos en los que se miran y fragmentan los personajes. Las voces de Novela como nube pueden percibirse como independientes, pero el autor se complace en crear la confusión, el lector se pregunta a cada momento qué pasa o quién habla. Los cambios de las palabras del narrador a las del personaje son, en ocasiones, imperceptibles. En la sintaxis, se usa el mínimo de conjunciones consecutivas, causales y adversativas, así como pocos adverbios temporales. Se presentan hechos, descripciones (casi cuadros o fotografías) y voces, sin más, como un collage. Los otros personajes se ven y escuchan desde la perspectiva de Ernesto, aunque enuncie el narrador.

El segmento vigésimo segundo es la "elegía en espiral”; ahora se conoce al poeta Ernesto en la lectura de una de sus creaciones, que narra las visitas del novio al balcón de la amada, con las interrupciones del sereno y el obstáculo de las ventanas: 
cárceles en abismo. Al "nuevo triste” y "nuevo romántico” del yo lírico de "Sindbad el varado", bien podría corresponder la afirmación del poeta Ernesto: "Era mil ochocientos ochenta y aún no descifraba James Joyce sus monólogos en espiral, pero ya se podían atar las cláusulas del discurso con el lazo sencillo de una consonancia, de un gesto, de un recuerdo" (177).

Ernesto, ahora narrador, no se olvida del humor, y entre la tragedia y la elegía hace un paréntesis declamatorio; como no recuerda el nombre de la amada, propone:

Vámonos a recordarla desde una estrella. Por el camino os contaré El impertinente, novela jamás concluida de G. Owen. Es ingenuo y feliz. Come con propiedad, pureza y elegancia. Ya lo veréis académico en 1990. Pero en castigo a este paréntesis, propongo que coloquen un espejo en su ataúd, para que se vaya viendo cómo se resuelve en cenizas (179).

En la cita anterior puede observarse que Owen emplea el recurso cervantino de crear narraciones dentro de la narración, como la de "El curioso impertinente" —que fue también el título de una sección de crítica literaria en la revista Contemporáneos donde colaboró Owen-, con el fin de hacer al autor partícipe de la ficción.

\section{A MANERA DE CONCLUSIÓN}

En Novela como nube se lucha contra la cronología de un relato tradicional, detalle que se remata con la inclusión del espejo en el ataúd, que podría interpretarse como la búsqueda de otra forma de representar el tiempo en el relato, ya que refiere cómo en el ataúd podría presenciarse la propia desintegración. Además, el espejo resume el juego con un personaje que se desdobla continuamente.

Sería cuestionable afirmar que en Novela... nada se cuenta, pues en la prosa de Owen se combinan técnicas narrativas complejas —algunas empleadas desde la antigüedad, como narraciones enmarcadas y puestas en abismo, o diálogos directos sin las acotaciones del narrador-, con procedimientos que se pusieron en práctica desde el simbolismo y que las vanguardias llevaron hasta las últimas consecuencias: simultaneísmo, objetivación, yuxtaposición de planos, tono conversacional, asociación libre, creación de imágenes desmotivadas. En las prosas de Owen hay narración y también poesía; es difícil apostar sólo a una parte: se trata de textos fronterizos.

El final de la novela subraya que Ernesto está escindido: "Ernesto el chino mira también desde el otro lado al Ernesto y al cielo occidentales: no puede sostener su mirada llena de siglos y de opio. La desvía poco a poco y se distrae” (180), pero está decidido a recuperar a su amada. Se insiste en la metáfora de la nube al aclarar que, cuando pasa una sombra, Ernesto la confunde con Elena —como Ixión creyó que sedujo a Hera, cuando se trataba de Néfele - y le pide una cita a la media noche (180-181). Ernesto cae en la cuenta de que la sombra era Amalia. El desenlace es claro: Amalia se deja seducir por Ernesto, quien, decepcionado, acepta que amó a "Elena inasible” en las otras mujeres; la condena es el matrimonio y la amargura que heredará a un hijo de Rosa Amalia. El único consuelo: saber que las mujeres "nunca se nos entregan, nunca nos dan más que una nube con su figura" (86). Este final trata de enderezar la trama para ofrecer un final claro, de manera que el lector pueda tener la impresión de que, a pesar del juego poético con las palabras y de las invitaciones a perderse, a desdoblarse junto con los personajes, ha leído una historia. 
En la obra oweniana el proceso de convertirse en otro con respecto a sí mismo como persona se repite al infinito, incluso cuando se trata del yo lírico de sus poemas. Owen reflexiona acerca del conocimiento del yo por la acción y la mirada del otro. El autor establece distancia respecto del personaje a través del narrador; sin embargo, a veces se ve un acercamiento en el que no se puede confiar demasiado, porque la identificación del autor, del yo lírico e, incluso, del personaje biográfico, se metamorfosea en la escritura; esta es la peculiaridad de la obra de Gilberto Owen. Quizá por eso Sergio Fernández dice que “su poesía es, por un casi, prosa; su prosa, por un casi, poesía” (Fernández 1991: 220).

\section{OBRAS CITADAS}

Archivo de La Parroquia de Nuestra Señora del Rosario. 1903-1905. Fe de bautismo de Gilberto Owen, vol. 43, libro 8, foja 48. Sinaloa, México.

Arredondo, Inés. 1982. “Apuntes para una biografía”. Revista de Bellas Artes 8: 43-48.

Archivo de la Universidad Autónoma del Estado de México. 1919. Expediente de Gilberto Estrada. Caja 171: 6646.

Breton, André. [1924] 2001. "Primer manifiesto del surrealismo (1924)". En Manifiestos del surrealismo. Trad. pról. y notas, Aldo Pellegrini. $2^{\mathrm{a}}$ ed. Buenos Aires: Argonauta. 19-62.

Calasso, Roberto. 2002. La literatura y los dioses. Trad. Edgardo Dobry. Barcelona: Anagrama.

Domínguez Michael, Christopher. 1994. “Los hijos de Ixión”. En Rafael Olea Franco y Anthony Stanton, Comps. Los Contemporáneos en el laberinto de la crítica. México: El Colegio de México. 225-236.

Falcón Martínez, Constantino. 1989. Diccionario de la mitología clásica. 2 vols. México: Alianza.

Fernández, Sergio. 1991. "El éter y el andrógino —aproximaciones a los Contemporáneos”En "El estiércol de Melibea” y otros ensayos. México: UNAM. 197-225.

Kundera, Milán. [1984] 2004. El arte de la novela. Trad. Fernando de Valenzuela y María Victoria Villaverde. Barcelona: Tusquets. 158-159.

Olea Franco, Rafael y Anthony Stanton, comps. 1994. Los Contemporáneos en el laberinto de la crítica, México: El Colegio de México.

Ortega y Gasset, José. [1925] 1983. La deshumanización del arte y otros ensayos de estética. $2^{\mathrm{a}}$ ed. Madrid: Revista de Occidente en Alianza Editorial.

Ortega, José Hilario. 1988. La personalidad poética de Gilberto Owen (tesis de doctorado). Austin: The University of Texas.

Owen, Gilberto. 1979. Obras. Josefina Procopio et al, Eds. Pról. Alí Chumacero. 2a ed. México: Fondo de Cultura Económica.

Rodó, José Enrique. [1900] 1982. Ariel (y Roberto Fernández Retamar, Calibán). Pról. y notas Abelardo Villegas. México: SEP/ UNAM. 13-76.

Sheridan, Guillermo. 1985. Los Contemporáneos ayer. México: Fondo de Cultura Económica.

Sontag, Susan. [1967] 1985. "La estética del silencio”. En Estilos radicales. Trad. Eduardo Goligorsky. Barcelona: Muchnik. 11-43.

Torres Souza, Ana Amalia; Barbosa Rocha, Zeferino Jesús. 2009. "No principio era a mythos: articulações entre mito, psicanálise e linguagem”. Estudos de Psicología 14. 3: 199-206 $<$ http://redalyc.uaemex.mx/src/inicio/ArtPdfRed.jsp?iCve=26113603003 $>$ [consulta: 15-02-2011].

Tzara, Tristan. [1924] 1963. “Manifeste de Monsieur Antipyrine”. En Sept manifestes Dada lampisteries. Montreuil: Jean-Jaques Pauvert. 15-17. 
